\title{
Impairment of neutrophil reactivity to elastin peptides in COPD
}

\author{
Aurélie Dupont, ${ }^{1}$ Sandra Dury, ${ }^{1,2}$ Valérie Gafa, ${ }^{1}$ François Lebargy, ${ }^{1,2}$ \\ Gaëtan Deslée, ${ }^{2,3}$ Moncef Guenounou, ${ }^{1}$ Frank Antonicelli, ${ }^{4}$ Richard Le Naour ${ }^{1}$
}

\begin{abstract}
- Additional material is published online only. To view please visit the journal online (http://dx.doi.org/10.1136/ thoraxjnl-2012-201833).

${ }^{1}$ EA4683, SFR CAP-Santé, Université de Reims Champagne-Ardenne, Reims, France

${ }^{2}$ Service des Maladies Respiratoires, Centre Hospitalier Universitaire, Reims France

${ }^{3}$ INSERM U903, SFR CAP. Santé, Université de Reims Champagne-Ardenne, Reims, France

${ }^{4}$ FRE3481, SFR CAP-Santé, Université de Reims Champagne-Ardenne, Reims, France
\end{abstract}

\section{Correspondence to}

Dr Richard Le Naour, EA4683, SFR CAP-Santé, 'Immunité Adaptative et Fonctionnalité des Barrières Biologiques', UFR de Pharmacie, Université de Reims Champagne-Ardenne, 1 rue du Marechal Juin, Reims cedex 51096, France; richard.lenaour@univ-reims.fr

Received 28 February 2012 Revised 18 December 2012 Accepted 20 December 2012 Published Online First 28 January 2013

To cite: Dupont A, Dury $S$ Gafa $V$, et al. Thorax 2013;68:421-428.

\section{ABSTRACT}

Rationale Neutrophils play an important role in the inflammatory process associated with chronic obstructive pulmonary disease (COPD). Lung-infiltrating neutrophils secrete elastinolytic proteases that participate in elastin breakdown and the formation of elastin peptides (EPs).

Objectives We hypothesized that circulating neutrophil-associated immune response may be modulated by EPs during COPD.

Methods Neutrophils obtained from patients with either stable or exacerbated COPD and controls were cultured with or without EPs. Cell chemotaxis was analysed by the Boyden method and cytokine expression was analysed by ELISA and real-time reverse transcriptase PCR. Bacterial phagocytosis and killing of ingested bacteria were evaluated after incubation with Pseudomonas aeruginosa. Reactive oxygen species (ROS) measurement and elastin receptor expression were determined by flow cytometry.

Results Chemotactic activity of neutrophils from patients with COPD towards the VGVAPG EP was reduced compared with controls. VGVAPG increased proinflammatory cytokine synthesis and bacterial load, but reduced ROS production in neutrophils from controls and from patients with stable COPD. Patients with exacerbated COPD were unresponsive to VGVAPG treatment. These findings were associated with a decreased or almost complete loss of S-Gal elastin receptor expression in neutrophils from patients with stable or exacerbated COPD, respectively.

Conclusions The study demonstrates that the response of neutrophils from patients with COPD to VGVAPG varied according to COPD phase and critical level of S-Gal expression. S-Gal downregulation could result from a feedback mechanism induced by high levels of EPs.

\section{INTRODUCTION}

Chronic obstructive pulmonary disease (COPD) is characterised by progressive airflow limitation associated with an abnormal inflammatory response of the lung to noxious particles or gases. ${ }^{1}$ COPD includes chronic bronchitis, with obstruction of small airways, and emphysema, characterised by the destruction of lung parenchyma responsible for loss of its elasticity. The inflammatory process occurring during COPD is characterised by activation of peripheral blood neutrophils and $\mathrm{T}$ lymphocytes, ${ }^{2}$ increased levels of proinflammatory cytokines in plasma and bronchoalveolar lavage (BAL), ${ }^{3}{ }^{4}$ and massive infiltration of leukocytes into the pulmonary parenchyma. ${ }^{5}$ The natural history of COPD is also characterised by recurrent phases of exacerbation.

\section{Key messages}

What is the key question?

- Do elastin peptides influence the innate immune response associated with chronic obstructive pulmonary disease (COPD) progression?

\section{What is the bottom line?}

- Decreased S-Gal elastin receptor expression during COPD impacts on neutrophil responses to elastin peptides.

\section{Why read on?}

- The critical level of S-Gal elastin receptor constitutes a new mechanism to control elastin peptide-dependent inflammation during exacerbations of COPD.

Most exacerbations involve pathogens and it is now established that $50 \%$ of exacerbations are caused by bacterial infection. Acquisition of a new strain of Haemophilus influenzae, Streptococcus pneumoniae or Pseudomonas aeruginosa is strongly associated with development of an exacerbation. ${ }^{6}$ Data from the literature show that the number of neutrophils in BAL from patients with COPD correlates with progression and severity of emphysema. ${ }^{7}$ Neutrophil recruitment is controlled by chemotactic mediators such as interleukin 8 (IL-8), growth regulated oncogene $\alpha$ (GRO- $\alpha)$ or regulated and normal T cell expressed and secreted (RANTES) ${ }^{8}$ and the bacterial clearance properties of neutrophils are dependent on reactive oxygen species (ROS) and granule-associated proteases. ${ }^{9} 10$

Proteases secreted by lung-infiltrating inflammatory cells participate in the tissue damage associated with COPD. ${ }^{11}$ Of interest, some of these proteases (neutrophil elastase, matrix metalloproteinase (MMP)-2 and 9) promote breakdown of elastin, a protein responsible for pulmonary elasticity. ${ }^{11} 12$ Accordingly, increased excretion of desmosine, a specific marker of elastin degradation, ${ }^{13}$ and elevated levels of elastin fragments in various biological fluids reflect massive pulmonary elastin breakdown in patients with COPD. ${ }^{14} 15$

Also of interest, it has been shown that elastin peptides (EPs) display a wide range of biological activities such as chemotactic activity, ${ }^{16}{ }^{17}$ regulation of cell proliferation ${ }^{18}$ and control of vascular 
tone. ${ }^{19}$ Moreover, they modulate the expression of proinflammatory cytokines. ${ }^{2021}$ EP effects are largely mediated via their interaction with a receptor complex, which includes a $67 \mathrm{kDa}$ elastin-binding protein (EBP or S-Gal) identified as an enzymatically inactive spliced variant of the human $\beta$-galactosidase. ${ }^{22}$ This elastin receptor complex is also composed of two other subunits named neuraminidase and protective protein/cathepsin $\mathrm{A}^{23}$

Since S-Gal is expressed on the surface of neutrophils ${ }^{24}$ and as EPs are largely generated during COPD, we hypothesized that the inflammatory and chemotactic properties of neutrophils may be modulated by EP/cell interactions during COPD progression, notably during the exacerbation phases associated with bacterial infection. In this study, we demonstrated that impairment of neutrophil reactivity to EPs was related to S-Gal elastin receptor downregulation in patients with COPD.

\section{METHODS}

\section{Study population}

Controls and patients with COPD were recruited from the Department of Respiratory Diseases, Reims University Hospital (France). Participation was entirely voluntary and all subjects gave their written informed consent prior to inclusion in the study. The study was approved by the University Hospital Ethics Committee. Additional data are given in the online supplementary data.

\section{Neutrophil isolation and culture}

Peripheral blood neutrophils were isolated from heparinised whole blood using a density gradient medium (Polymorphprep, Abcys Biology, Paris, France) and magnetic-activated cell sorting using CD16 microbeads (Miltenyi Biotec, Paris, France). Additional data are given in the online supplementary data.

\section{Neutrophil treatment with EP}

Neutrophils were incubated in the presence or absence of 1 or $10 \mu \mathrm{g} / \mathrm{ml}$ VGVAPG (Genepep, Prades le Lez, France) for $4 \mathrm{~h}$. Neutrophils were then either collected for total RNA extraction or for elastin receptor staining. Cell culture supernatants were collected for cytokine quantification by ELISA. In some experiments, pretreatment of neutrophils for $1 \mathrm{~h}$ with $10 \mathrm{mM}$ lactose (Sigma-Aldrich, Saint Quentin Fallavier, France), a galactosugar known to induce S-Gal shedding from the cell surface, ${ }^{25}$ was used to assess the specificity of VGVAPG effects. For phagocytosis assay, neutrophils were pretreated with VGVAPG $(1 \mu \mathrm{g} / \mathrm{ml}, 4 \mathrm{~h})$ before incubation with fluorescent latex beads. For bacterial load and ROS measurements, neutrophils were pretreated with VGVAPG $(1$ or $10 \mu \mathrm{g} / \mathrm{ml}, 4 \mathrm{~h})$ before incubation with $P$ aeruginosa.

\section{Neutrophil chemotaxis assay}

Neutrophil chemotactic activity was determined using a Boyden chamber method. Additional data are given in the online supplementary data.

\section{Real-time RT-PCR analysis}

Full details are given in the online supplementary data.

\section{Flow cytometric analysis}

Elastin binding on human neutrophils was determined after $30 \mathrm{~min}$ incubation with elastin-FITC $(1 \mu \mathrm{g} / \mathrm{ml})$ (Elastin Products Company, Owensville, Missouri, USA), as previously described ${ }^{20}$ and fluorescence emission was assessed by flow cytometric analysis using a FACSCalibur Instrument (BD Biosciences, Le Pont de
Claix, France). Specificity of elastin binding on neutrophils was determined by pretreatment of cells with lactose $(10 \mathrm{mM}, 1 \mathrm{~h})$ inhibiting elastin binding to cells (data not shown). In some experiments, neutrophils from controls were pretreated for $4 \mathrm{~h}$ with VGVAPG (1 or $10 \mu \mathrm{g} / \mathrm{ml}$ ) before incubation with elastin-FITC.

\section{Detection of cytokine concentration}

Determination of IL-6, tumour necrosis factor $\alpha$ (TNF $\alpha)$ and IL-8 in neutrophil cell culture supernatants was performed in triplicate using commercially available high-sensitivity ELISA kits (Quantikine, R\&D Systems, Lille Cedex, France) according to the manufacturer's instructions. The sensitivity of each ELISA kit was $0.70 \mathrm{pg} / \mathrm{ml}, 4.4 \mathrm{pg} / \mathrm{ml}$ and $1.5 \mathrm{pg} / \mathrm{ml}$, respectively.

\section{Phagocytosis assay}

Phagocytosis assay was performed following incubation of neutrophils with red fluorescent latex beads. Additional data are given in the online supplementary data.

\section{Neutrophil-associated bacteria and intracellular ROS measurements}

Full details are given in the online supplementary data.

\section{Determination of serum elastin-derived peptide concentration}

In additional subjects, including healthy subjects $(n=5)$, patients with stable COPD $(n=5)$ and COPD exacerbation $(n=5)$, the serum elastin-derived peptide concentration was determined using a competitive ELISA adapted from a protocol described by Smith $e t a l{ }^{26}$ Additional data are given in the online supplementary data.

\section{Statistical analysis}

Data are presented as median and IQR range for $\mathrm{n}$ observations. Comparisons within the same groups were performed using a Wilcoxon test. Comparisons between groups of subjects were performed using a Kruskal-Wallis test. Differences were considered significant for $\mathrm{p}<0.05$.

\section{RESULTS}

\section{Clinical features of study populations}

Clinical characteristics of patients with COPD and controls are summarised in table 1 . As expected, significant differences in airway limitation and static hyperinflation were observed

Table 1 Characteristics of the study groups

\begin{tabular}{|c|c|c|c|}
\hline & \multirow[b]{2}{*}{ Controls } & \multicolumn{2}{|c|}{ Patients with COPD } \\
\hline & & Exacerbated & Stable \\
\hline Subjects & 20 & 16 & 11 \\
\hline Age (years) & $55 \pm 10$ & $66 \pm 10$ & $64 \pm 8$ \\
\hline Current smokers \% & 52.6 & 46.1 & 57.1 \\
\hline Smoking history & $23.4 \pm 19.4$ & $51 \pm 18.7^{*}$ & $50.5 \pm 14.8^{*}$ \\
\hline \multicolumn{4}{|l|}{ Pack-years $\dagger$} \\
\hline $\mathrm{FEV}_{1} \%$ predicted & $98.6 \pm 10.4$ & - & $51.2 \pm 17.1^{*}$ \\
\hline $\mathrm{FEV}_{1} / \mathrm{FVC} \%$ & $79.8 \pm 8.2$ & - & $48.8 \pm 10.8^{*}$ \\
\hline Neutrophils $/ \mathrm{mm}^{3}$ & $5529 \pm 1777$ & $6729 \pm 2326$ & $5136 \pm 1630$ \\
\hline \multicolumn{4}{|c|}{$\begin{array}{l}\text { Data are presented as mean } \pm \text { SD or } \% \text {, unless otherwise stated. } \\
{ }^{*} p<0.05 \text { vs controls. } \\
+1 \text { pack-year represents } 20 \text { cigarettes per day for } 1 \text { year. } \\
\text { COPD, chronic obstructive pulmonary disease; } \mathrm{FEV}_{1} \text {, forced expiratory volume in } 1 \mathrm{~s} \text {; } \\
\text { FVC, forced vital capacity. }\end{array}$} \\
\hline
\end{tabular}


between patients with COPD and controls. Furthermore, cumulative smoking exposure was significantly higher in patients with stable and exacerbated COPD than in controls. No significant difference was observed between the three groups in terms of the mean age of the subjects, the percent of current smokers and the neutrophil count.

\section{Neutrophil chemotaxis towards VGVAPG is altered during COPD}

Neutrophil chemotaxis was analysed in 16 patients with exacerbated COPD, 11 with stable COPD following resolution of the exacerbation, and 20 controls. The results showed that $1 \mu \mathrm{g} / \mathrm{ml}$ VGVAPG, used as chemoattractant, significantly enhanced the chemotactic activities of neutrophils from controls (figure 1A, $p=0.02$ ). This was further confirmed by analysing samples obtained from the same patient during stable and exacerbation phases of COPD (data not shown). Preincubation of neutrophils with lactose totally abolished the VGVAPG-induced chemotactic effect on neutrophils from controls (figure 1B, $\mathrm{p}=0.02$ ). However, the VGVAPG chemotactic effect on neutrophils from controls was not reproduced when this peptide was used at a higher concentration $(10 \mu \mathrm{g} / \mathrm{ml})$ (figure 1A). No VGVAPG-dependent chemotaxis was observed with neutrophils from patients with either stable or exacerbated COPD, regardless of the peptide concentration used (figure 1A). Nevertheless, analysis of chemotaxis towards RANTES, used as a pathophysiological chemoattractant with regard to COPD, showed that the migratory capacities of neutrophils from both COPD patient groups were preserved, with similar magnitudes to those observed in the control group (figure 1A). This effect was not dependent on lactose pretreatment (figure 1B).

\section{VGVAPG effects on neutrophil cytokine expression are dependent on clinical status}

As EPs modulate the expression of proinflammatory cytokines in human monocytes and lymphocytes, ${ }^{20} 27$ we then investigated whether VGVAPG altered IL- 6 , TNF $\alpha$ and IL- 8 production in neutrophils from patients with COPD and controls. Treatment with VGVAPG $(1 \mu \mathrm{g} / \mathrm{ml})$ significantly increased IL-6 mRNA expression in neutrophils from controls and patients with stable COPD, but had no effect on IL-6 expression in neutrophils from patients with exacerbated COPD (figure 2A). These variations were also clearly demonstrated by ELISA analysis of IL-6 protein secretion (figure 2B). However, treatment of neutrophils with a higher concentration of VGVAPG $(10 \mu \mathrm{g} / \mathrm{ml})$ did not modify IL-6 expression in either controls or patients with stable COPD, while patients with exacerbated COPD still failed to respond (figure 2A,B). Similar effects were observed on TNF $\alpha$ expression in neutrophils treated with VGVAPG in controls and patients with COPD (figure 2D,E).
Figure 1 Neutrophil chemotactic response towards VGVAPG in controls and patients with chronic obstructive pulmonary disease. (A) Neutrophils from controls $(n=20)$ and patients with either stable $(n=11)$ or exacerbated $(n=16)$ COPD were added to the upper wells of a Boyden chamber and studied for their chemotactic response to VGVAPG (1 and $10 \mu \mathrm{g} / \mathrm{ml}$ ) or regulated and normal T cell expressed and secreted (RANTES) $(0.1 \mu \mathrm{g} / \mathrm{ml}$; positive control) added to the lower wells. The number of migrating cells was determined after 45 min of incubation and staining with eosin and bromophenol blue. (B) Neutrophils isolated from controls $(n=7)$ and from patients with COPD $(n=5)$ sampled at the exacerbation and stable phases were pretreated with or without lactose for $1 \mathrm{~h}$ and studied for their chemotactic response to $1 \mu \mathrm{g} / \mathrm{ml}$ VGVAPG.

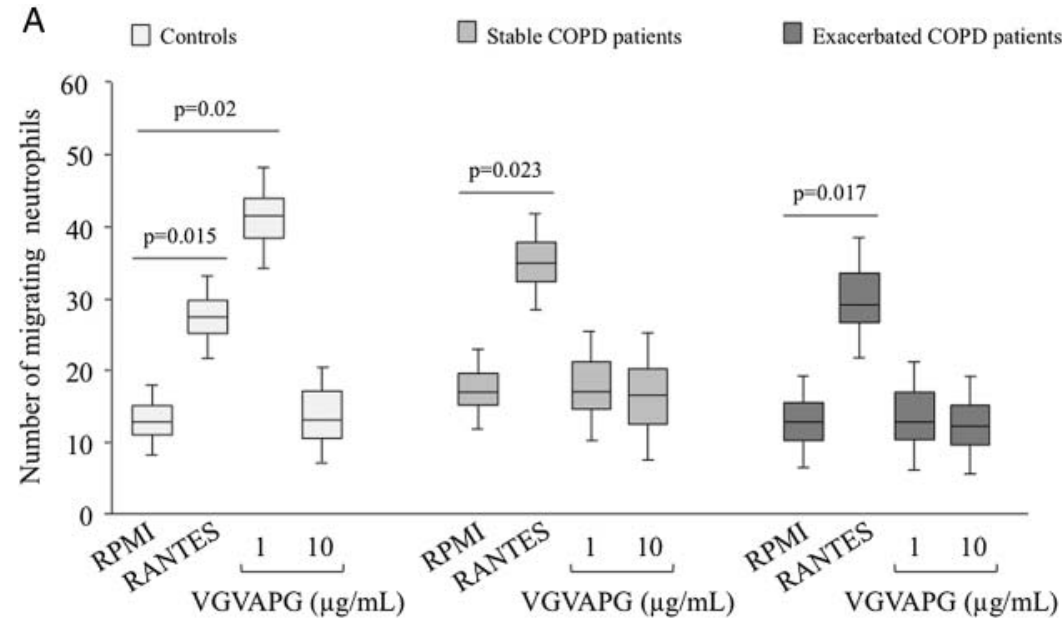

B

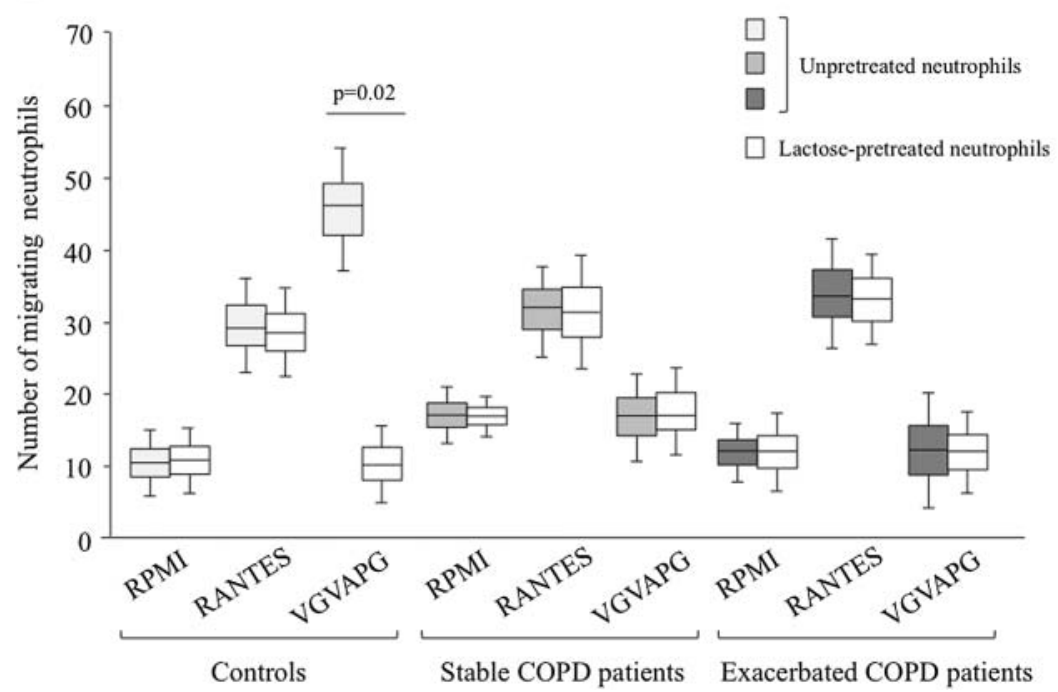



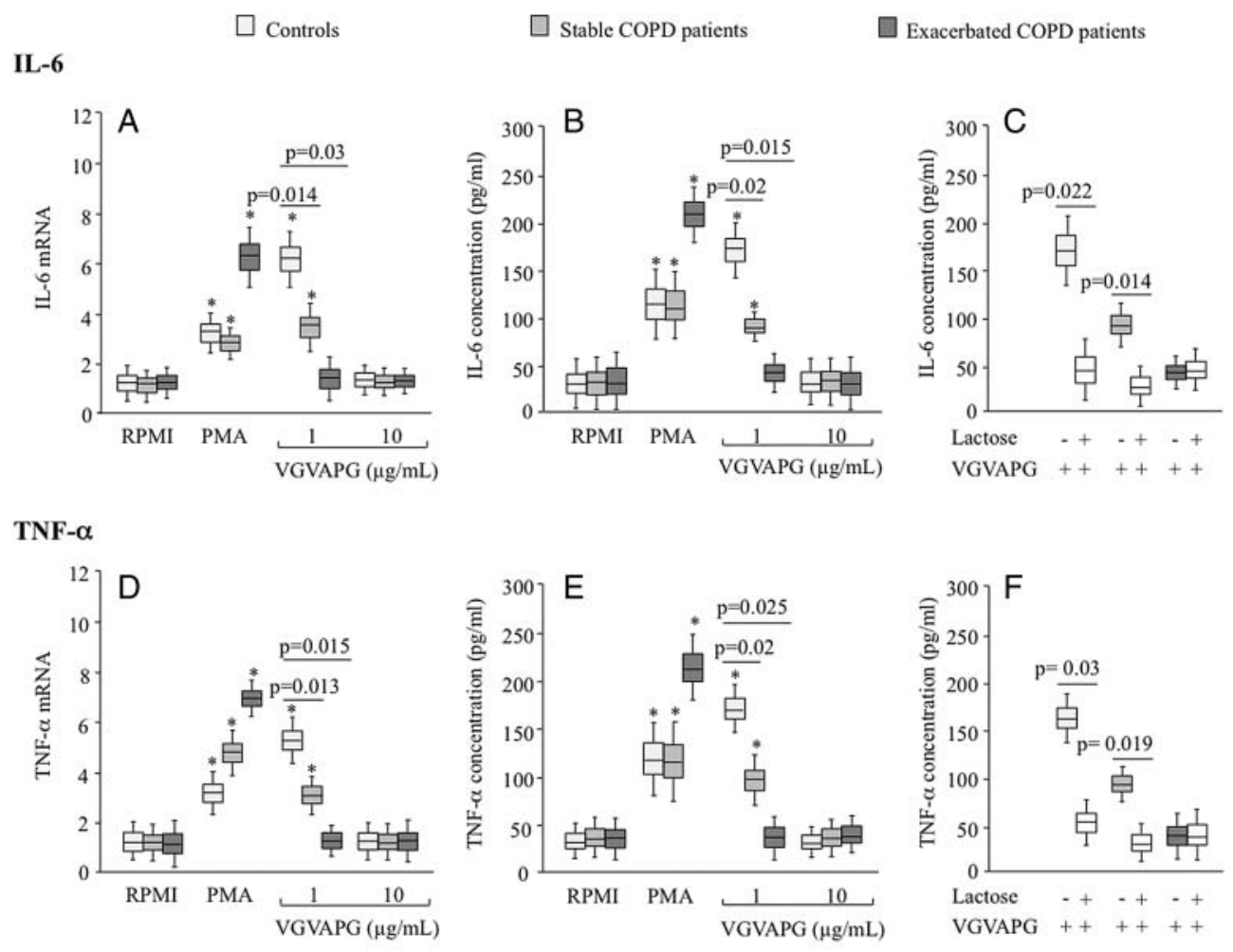

\section{IL-8}
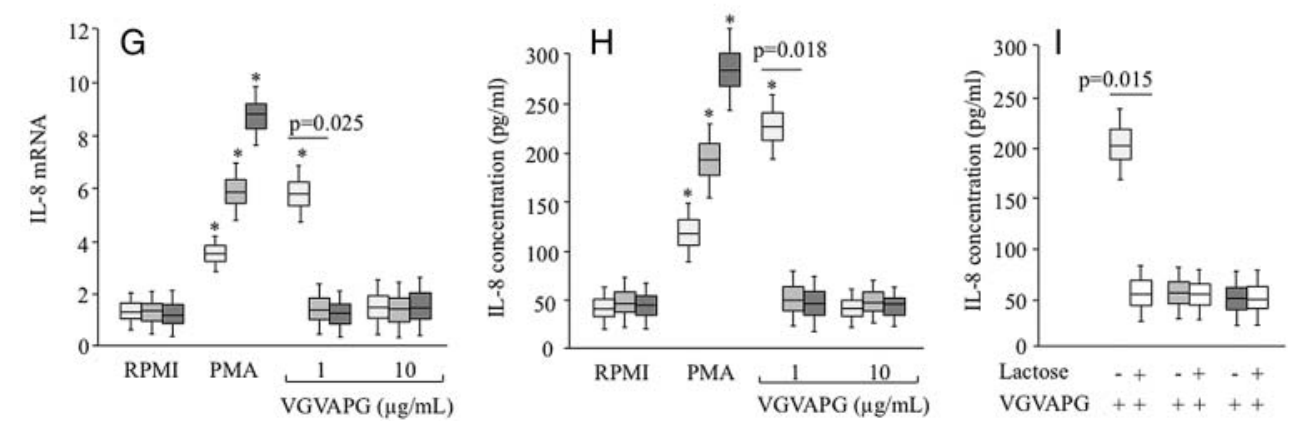

Figure 2 Effects of VGVAPG on cytokine expression by neutrophils isolated from controls and patients with chronic obstructive pulmonary disease. Neutrophils isolated from controls $(n=16)$ and from patients with COPD $(n=9)$ sampled during exacerbation and stable phases were treated with PMA $(1 \mu \mathrm{M})$ or VGVAPG (1 and $10 \mu \mathrm{g} / \mathrm{ml})$. Four hours after treatment, mRNA expression and interleukin (IL)- 6 (A,B), tumour necrosis factor (TNF)- $\alpha$ $(D, E)$ and IL-8 $(G, H)$ cytokine secretions were determined by real-time reverse transcriptase PCR and by ELISA, respectively. *Significant difference in cytokine expression/secretion compared with RPMI in the same cohort $(p<0.05)$. In some experiments neutrophils from controls $(n=10)$ and patients with COPD $(n=6)$ were preincubated for $1 \mathrm{~h}$ with lactose before treatment with $1 \mu \mathrm{g} / \mathrm{ml}$ VGVAPG. Four hours after treatment, IL-6 (C), TNF $\alpha(\mathrm{F})$ and IL-8 (I) cytokine secretions were determined by ELISA.

Increased expression of IL-6 and TNF $\alpha$ in controls and patients with stable COPD in response to $1 \mu \mathrm{g} / \mathrm{ml}$ VGVAPG treatment was abolished by pretreatment of neutrophils with lactose (figure 2C,F). In contrast, although VGVAPG induced IL-8 expression by neutrophils from controls (figure $2 \mathrm{G}, \mathrm{H}$ ) in a lactose-dependent manner (figure 2I), this peptide did not affect IL-8 expression in neutrophils from patients with stable COPD regardless of the concentration used. Of note, treatment with phorbol myristate acetate (PMA) increased the expression of all cytokines analysed, but with a greater susceptibility of neutrophils to PMA in patients with exacerbated COPD compared with those with stable COPD and controls.

\section{VGVAPG affects bacterial load and ROS production only in the stable phase of COPD}

To further characterise the biological properties of neutrophils from each group, we also investigated their capacity to ingest and kill bacteria. For this purpose, we first measured the number of colony-forming units (CFUs) corresponding to the total bacterial load present in neutrophils incubated with $P$ aeruginosa. Kinetic analysis showed that CFU number associated with neutrophils from patients with exacerbated COPD was already maximal after 30 min of incubation with $P$ aeruginosa. At 30 min, patients with stable COPD had a reduced CFU number compared with patients with COPD exacerbation $(p=0.014)$, which was nevertheless significantly enhanced compared with controls (figure 3A). However, when measured after $90 \mathrm{~min}$, bacterial load was similar in patients with stable and exacerbated COPD (figure 3B). Pretreatment of neutrophils with VGVAPG $(1 \mu \mathrm{g} / \mathrm{ml}, 4 \mathrm{~h})$ significantly increased the CFU number at 30 and $90 \mathrm{~min}$ in patients with stable COPD and controls, but not in those with exacerbated COPD (figure 3A, B). Regardless of the time point and the neutrophil groups analysed, $10 \mu \mathrm{g} / \mathrm{ml}$ VGVAPG did not alter the CFU number (figure $3 \mathrm{~A}, \mathrm{~B})$. We then determined whether the increased intracellular 
Figure 3 Effects of VGVAPG on bacterial load, phagocytosis and reactive oxygen species (ROS) production by neutrophils isolated from controls and patients with chronic obstructive pulmonary disease (COPD). $(A, B)$ Neutrophils isolated from controls $(n=20)$ and patients with COPD $(n=11)$ sampled during exacerbation and stable phases were pretreated with or without VGVAPG before incubation with Pseudomonas aeruginosa. Neutrophil bacterial load analysed $30 \mathrm{~min}(\mathrm{~A})$ and $90 \mathrm{~min}$ (B) after $P$ aeruginosa incubation was determined by number of $24 \mathrm{~h}$ after culture of neutrophil-associated bacteria in a specific medium. $(C, D)$ Neutrophils isolated from controls $(n=5)$ and patients with COPD $(n=5)$ sampled during exacerbation and stable phases were pretreated with or without VGVAPG $(1 \mu \mathrm{g} / \mathrm{ml}, 4 \mathrm{~h})$ before incubation with fluorescent latex beads. Neutrophil phagocytic activity analysed $30 \mathrm{~min}$ (C) and $90 \mathrm{~min}$ (D) after fluorescent latex bead incubation was determined by flow cytometry. $(\mathrm{E}, \mathrm{F})$ Neutrophils isolated from controls $(n=20)$ and patients with COPD $(n=11)$ sampled at exacerbation and stable phases were pretreated with or without VGVAPG before incubation analysed at $30 \mathrm{~min}(\mathrm{E})$ and $90 \mathrm{~min}$ (F) after incubation was determined by flow cytometric analysis. *Significant difference in bacterial load, phagocytic activity and ROS production compared with RPMI from controls $(p<0.05)$; ${ }^{* *}$ significant difference in bacterial load, phagocytic activity and ROS production compared with RPMI in the same cohort $(p<0.05)$. colony-forming units (CFUs) obtained with $P$ aeruginosa. ROS production
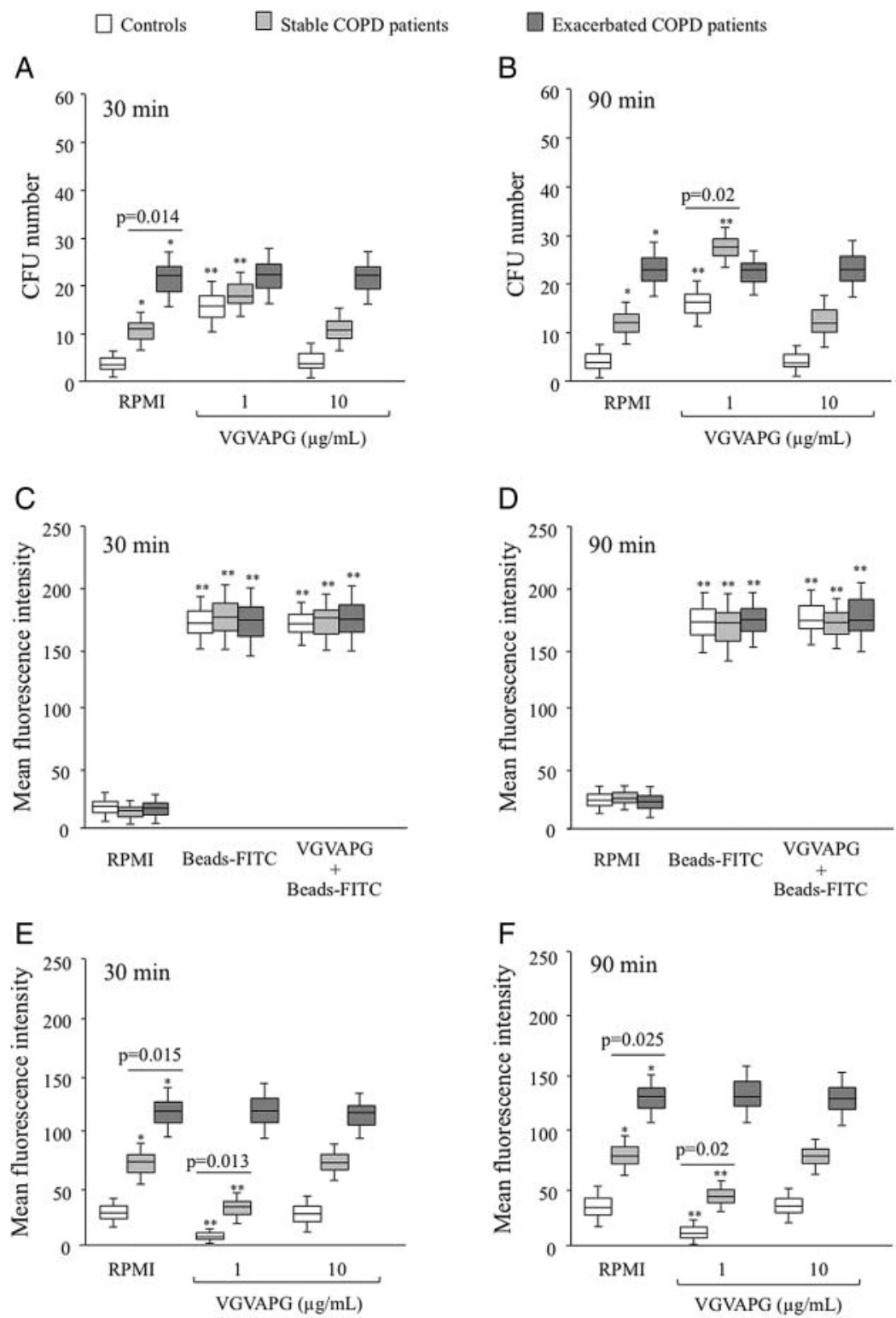

bacterial numbers could result from enhanced phagocytosis and/or reduced killing. Results from figure 3C,D showed that the phagocytosis capacity of neutrophils was not altered during COPD, either in the presence or in the absence of VGVAPG. Conversely, ROS production, constituting a marker of the neutrophil bactericidal process, was significantly higher in patients with exacerbated COPD than in those with stable COPD $(p=0.015)$ and controls (figure 3E). Upon VGVAPG stimulation $(1 \mu \mathrm{g} / \mathrm{ml})$, ROS levels decreased in controls and in the stable COPD group, whereas patients with exacerbated COPD were unresponsive to this treatment. Similar effects were observed at 30 and $90 \mathrm{~min}$ (figure 3E, F). As in all experiments, $10 \mu \mathrm{g} / \mathrm{ml} \mathrm{VGVAPG}$ was ineffective to modulate neutrophil ROS production. Globally, these results are suggestive of alterations in bactericidal activity rather than uptake.

\section{Elastin receptor expression on neutrophil surface is downregulated during COPD}

To further address the relationship between the biological responses of neutrophils towards VGVAPG and COPD phases, we hypothesized that elastin receptor expression on the neutrophil surface could represent a critical mechanism to explain the differential effects observed. Protein elastin receptor quantification by flow cytometry using elastin-FITC revealed a high constitutive level of elastin receptor on the surface of neutrophils from controls (figure 4A). This expression was markedly reduced on the surface of neutrophils from patients with stable COPD, and almost completely abolished on neutrophils from patients with exacerbated COPD (figure 4A). The statistical significance of this result was confirmed by studying eight different donors (figure 4B). To further characterise the receptor involved in VGVAPG effects, we then analysed S-Gal mRNA expression by real-time reverse transcriptase (RT)-PCR. Compared with controls, quantification of S-Gal mRNA expression in neutrophils from patients with stable and exacerbated COPD revealed a 3.0-fold and 7.7-fold reduced S-Gal level, respectively (figure 4C). To further investigate whether this S-Gal downregulation was related to EP production, we determined the level of these peptides in sera from patients with COPD with respect to controls. Figure 5A shows that patients with exacerbated COPD exhibited significantly higher levels of 
Figure 4 S-Gal expression on neutrophils isolated from controls and patients with chronic obstructive pulmonary disease (COPD). Neutrophils from controls and patients with COPD sampled during exacerbation and stable phases were incubated with or without elastin-FITC (1 $\mu \mathrm{g} / \mathrm{ml}, 30 \mathrm{~min})$ and elastin binding on cells was determined by flow cytometry analysis. (A) The data of one representative experiment are presented. (B) Statistical analysis of results obtained from eight independent experiments. Data are expressed as mean fluorescence intensity. The negative control was obtained with neutrophils isolated from the three groups $(n=24)$ and not treated with elastin-FITC. (C) Total RNA was extracted from neutrophils from controls $(n=20)$ and from patients with either stable $(n=11)$ or exacerbated $(n=16)$ COPD and S-Gal mRNA expression was determined by real-time reverse transcriptase PCR. This figure is only reproduced in colour in the online version.

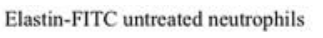

$$
\text { Elastin-FITC treated neutrophils } \begin{cases}\square & \text { Controls } \\ \square & \text { Stable COPD patients } \\ \square & \text { Exacerbated COPD patients }\end{cases}
$$

A

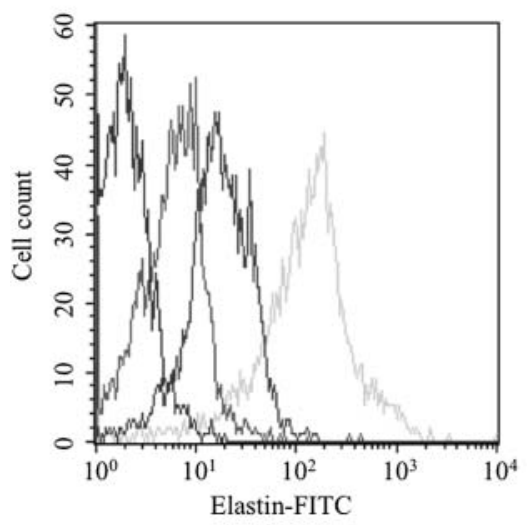

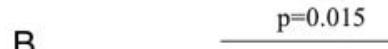

B

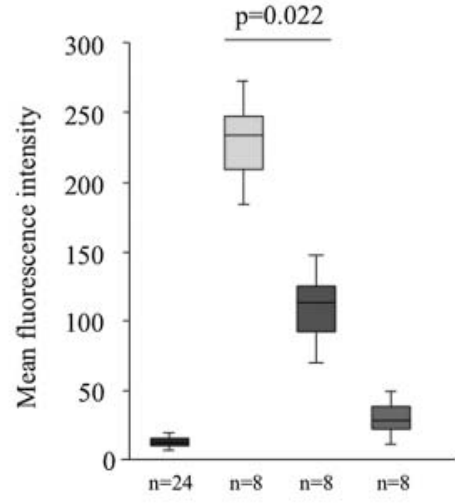

C



EPs than patients with stable COPD, and these levels were also higher than in controls. We therefore hypothesized that S-Gal receptor expression on the neutrophil surface could be downregulated by high EP concentrations. To investigate this hypothesis, neutrophils from controls were preincubated with VGVAPG before elastin receptor determination. Treatment with $10 \mu \mathrm{g} / \mathrm{ml}$ VGVAPG markedly decreased elastin receptor expression, whereas no significant effect was observed with a concentration of $1 \mu \mathrm{g} / \mathrm{ml}$ (figure 5B). This result was also observed at the protein level and was statistically confirmed by studying six different donors (figure 5C,D).

\section{DISCUSSION}

EPs produced by the degradation of lung connective tissue are known to share miscellaneous biological properties. It has been shown that EPs could alter adaptive immunity by facilitating $\mathrm{T}$ helper 1 polarisation of $\mathrm{T}$ lymphocyte ${ }^{27}$ and could also initiate the autoimmune process in the lung. ${ }^{28}$ The present study was designed to assess, in healthy subjects and in patients with COPD, the effects of EPs on peripheral polymorphonuclear (PMN) cells, a major component of the innate immune process.

Neutrophils from healthy subjects demonstrated increased chemotaxis in response to EP, which is in agreement with previous studies. ${ }^{29} 30$ Moreover, EP induced synthesis and release of IL-6, IL-8 and TNF $\alpha$, proinflammatory cytokines known to be strong neutrophil activators. EP pretreatment of neutrophils from healthy subjects exposed to bacteria also increased the intracellular concentration of bacteria, suggesting alteration of their bactericidal properties related to reduced ROS production rather than defective phagocytosis function. In healthy subjects, therefore, it can be postulated that EPs exert proinflammatory properties consisting of neutrophil chemotaxis and inflammatory cytokine release, but paradoxically alter ROS production and consequently the clearance of bacteria. Apart from chemotaxis, similar results were obtained in patients with stable COPD. Thus, cytokine production (IL- 6 and TNF $\alpha$ ) and bactericidal function displayed the same patterns as in healthy subjects when neutrophils were stimulated with EPs. A recent study demonstrated that neutrophils were rapidly recruited from the circulation during pulmonary inflammation. ${ }^{31}$ EPs do not seem to be involved in this migration in patients with stable COPD. Previous studies have demonstrated that EP effects are largely mediated via their interaction with a receptor which includes the EBP S-Gal. ${ }^{22}$ We have previously established a correlation between cytokine production and S-Gal receptor expression in EP-treated immune cells. ${ }^{20} 27$ In the present study, we demonstrated that the effects of EPs on neutrophil migration, cytokine release and ROS production were mediated via the elastin receptor, as lactose, the natural elastin receptor agonist, blocked EP-related changes. Interestingly, it has been reported that 
Figure 5 Serum elastin peptide (EP) levels in patients with chronic obstructive pulmonary disease (COPD) and S-Gal expression on

VGVAPG-treated neutrophils isolated from controls. (A) EP concentrations in serum from controls $(n=5)$ and patients with either stable $(n=5)$ or exacerbated $(n=5)$ COPD were determined by competitive ELISA. Standards and variable dilutions of serum samples were analysed in triplicate. EP concentrations were calculated from the standard curve and expressed as micrograms per millilitre.

(B) Neutrophils from controls $(n=12)$ were treated with VGVAPG (1 or $10 \mu \mathrm{g} / \mathrm{ml}, 4 \mathrm{~h}$ ) and total RNA was extracted to analyse $\mathrm{S}$-Gal mRNA expression by real-time reverse transcriptase PCR. (C) Neutrophils from controls were treated with or without VGVAPG (1 or $10 \mu \mathrm{g} / \mathrm{ml}, 4 \mathrm{~h}$ ), then incubated with elastin-FITC $(1 \mu \mathrm{g} / \mathrm{ml}$, $30 \mathrm{~min}$ ). Elastin binding on neutrophils was determined by flow cytometry analysis. The data of one representative experiment are presented. (D) Statistical analysis of results obtained from six independent experiments studying elastin binding on neutrophils from controls. Data are expressed as mean fluorescence intensity. The negative control was obtained with neutrophils isolated from the three groups $(n=18)$ and neither treated with VGVAPG nor stained with elastin-FITC. This figure is only reproduced in colour in the online version.
A

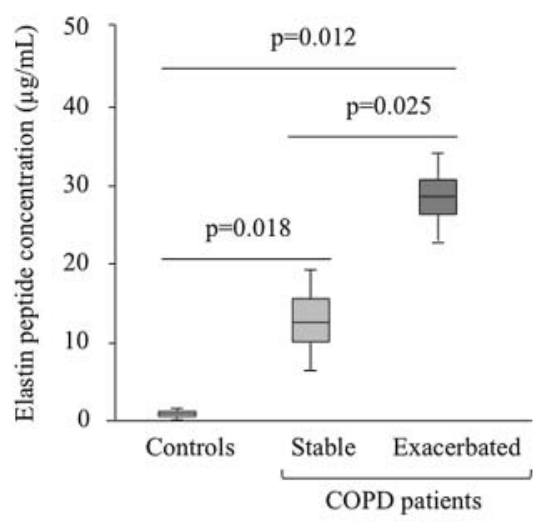

B
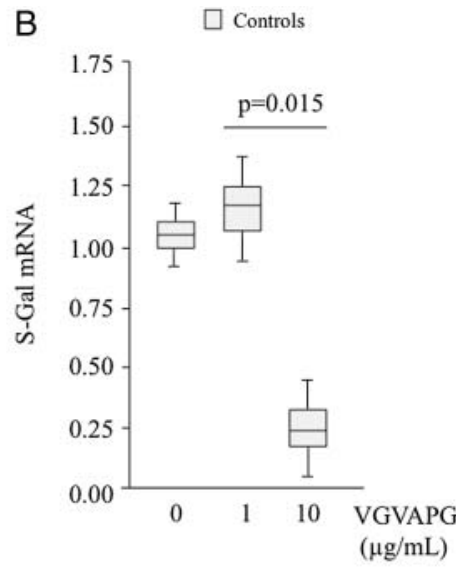



COPD and emphysema are associated with increased EP production due to excessive breakdown of lung matrix components. ${ }^{13}$ It can therefore be hypothesized that in the stable state, excess EP production could participate in the chronic inflammatory process and susceptibility to infection in COPD.

COPD exacerbations are known to be characterised by a burst of systemic and airways inflammation. This condition is associated with many clinical, biological and physiological changes. $^{32}$ The present study demonstrated that neutrophil chemotaxis in response to EPs was abolished in patients with exacerbated COPD, as already observed in patients with stable COPD. Consistent with these results, previous studies demonstrated that neutrophil migration induced by N-Formyl-Met-Leu Phe (fMLP) or IL-8 was reduced in patients with moderate to severe COPD compared with patients with mild COPD and healthy controls. As in our study, no difference was observed between smoking and non-smoking healthy individuals, suggesting that smoking did not influence in vitro neutrophil migration. ${ }^{33}{ }^{34}$ Conversely, it has been demonstrated that cigarette smoke extract induces a direct migratory effect on neutrophils via a $\beta 2$ integrin-dependent mechanism. ${ }^{35}$ The discrepancy between these studies could be explained by the difference in their experimental design, as the first studies used neutrophils exposed in vivo to tobacco and the last study used 'naive' neutrophils exposed to cigarette smoke extract in vitro. Similarly, we showed that neutrophils from patients with exacerbated COPD were unresponsive to EP stimulation for cytokine production. Furthermore, neutrophils from patients with exacerbated COPD produced high levels of ROS, but were unable to clear pathogens, with or without EP stimulation. As phagocytosis function and ROS production were preserved in patients with exacerbated COPD, we suggest that loss of killing function in neutrophils could be due to alteration in the killing process of bacteria unrelated to ROS production.

Due to the unresponsiveness of neutrophils to EPs in exacerbated COPD, we addressed the issue of S-Gal receptor expression and in vivo EP production in patients with exacerbated COPD. Our results showed that S-Gal receptor expression was markedly reduced in the stable state and almost completely abolished during exacerbation. Furthermore, EP concentrations were increased in patients with COPD and twofold higher during exacerbation than in the stable state. These results are consistent with those of previous studies reporting enhanced plasma, urine and alveolar concentrations of EPs in patients with COPD. ${ }^{14}$ Furthermore, it has been shown that EP concentrations were increased in BAL fluid from smokers and correlated with neutrophil elastase activity, supporting the theory of protease/antiprotease imbalance. ${ }^{15} \mathrm{It}$ 
has previously been demonstrated that S-Gal located on the cell membrane surface could be internalised in the presence of tropoelastin. ${ }^{36}$ Since enhancement of plasma EP and S-Gal receptor downregulation were demonstrated in patients with COPD in the stable state and during exacerbation, we postulated that elastin receptor expression could be regulated by EP concentrations. In support of this hypothesis, the present study showed that S-Gal level on neutrophils was drastically reduced by high EP concentrations in vitro, suggesting a putative downregulation of elastin receptor in the presence of high EP concentrations in COPD.

In conclusion, COPD outcome is characterised by recurrent episodes of exacerbation associated with the acute inflammatory process. Our results showed that plasma EP concentrations are enhanced in patients with stable COPD and twofold higher during exacerbation. Peripheral blood neutrophils from patients with stable COPD displayed altered cytokine release and ROS production in response to EP stimulation. Furthermore, during exacerbation, neutrophils became unresponsive to EP stimulation, a condition associated with downregulation of elastin receptor on the neutrophil membrane surface. This study therefore suggests that COPD exacerbations are associated with EP-dependent alteration of PMN functions and changes in innate immunity.

Acknowledgements The authors would like to thank Prof S Gangloff for her technical assistance in determination of the number of neutrophil-associated bacteria.

Contributors FL, FA and RLN contributed equally to this work.

Funding Aurélie Dupont received a grant for doctoral training from the Ministère de l'Enseignement Supérieur et de la Recherche (Paris, France). This work was supported by grants from the Contrat Projet Etat Région (2007-2013).

\section{Competing interest None.}

Patient consent Obtained.

Ethics approval This study was conducted with the approval of the Reims University Hospital Ethics Committee.

Provenance and peer review Not commissioned; externally peer reviewed.

\section{REFERENCES}

1 Global Initiative for Chronic Obstructive Lung Disease (GOLD). Global Strategy for Diagnosis, Management, and Prevention of Chronic Obstructive Pulmonary Disease, 2010. http://www.goldcopd.org (accessed Aug 2011).

2 Agustí AG, Noguera A, Sauleda J, et al. Systemic effects of chronic obstructive pulmonary disease. Eur Respir J 2003;21:347-60.

3 Chung KF. Cytokines in chronic obstructive pulmonary disease. Eur Respir J 2001;18 (Suppl 34):50s-9s.

4 Pinto-Plata VM, Livnat G, Girish M, et al. Systemic cytokines, clinical and physiological changes in patients hospitalized for exacerbation of COPD. Chest 2007; 131:37-43.

5 Barnes PJ. New concepts in chronic obstructive pulmonary disease. Annu Rev Med 2003:54:113-29

6 Sethi S, Murphy TF. Infection in the pathogenesis and course of chronic obstructive pulmonary disease. N Engl J Med 2008;359:2355-65.

7 Barnes PJ. Chronic obstructive pulmonary disease. N Engl J Med 2000:343:269-80.

8 Rot $A$, von Andrian UH. Chemokines in innate and adaptive host defense: basic chemokinese grammar for immune cells. Annu Rev Immunol 2004;22:891-928.

9 Reeves EP, Lu H, Jacobs HL, et al. Killing activity of neutrophils is mediated through activation of proteases by K1 flux. Nature 2002:416:291-7.

10 Borregaard N, Cowland JB. Granules of the human neutrophilic polymorphonuclear leukocyte. Blood 1997:89:3503-21.

11 Owen CA. Proteinases and oxidants as targets in the treatment of chronic obstructive pulmonary disease. Proc Am Thorac Soc 2005:2:373-85.
12 Lombard C, Arzel L, Bouchu D, et al. Human leukocyte elastase hydrolysis of peptides derived from human elastin exon 24. Biochimie 2006;88:1915-21.

13 Gottlieb DJ, Stone PJ, Sparrow D, et al. Urinary desmosine excretion in smokers with and without rapid decline of lung function: the Normative Aging Study. Am J Respir Crit Care Med 1996;154:1290-95.

14 Schriver EE, Davidson JM, Sutcliffe MC, et al. Comparison of elastin peptide concentrations in body fluids from healthy volunteers, smokers, and patients with chronic obstructive pulmonary disease. Am Rev Respir Dis 1992;145:762-6.

15 Betsuyaku T, Nishimura M, Yoshioka A, et al. Elastin-derived peptides and neutrophil elastase in bronchoalveolar lavage fluid. Am J Respir Crit Care Med 1996;154:720-4.

16 Senior RM, Griffin GL, Mecham RP. Chemotactic responses of fibroblasts to tropoelastin and elastin-derived peptides. J Clin Invest 1982;70:614-18.

17 Senior RM, Griffin GL, Mecham RP, et al. Val-Gly-Val-Ala-Pro-Gly, a repeating peptide in elastin, is chemotactic for fibroblasts and monocytes. J Cell Biol 1984;99:870-4.

18 Ghuysen-Itard AF, Robert $L$, Jacob MP. Effect of elastin peptides on cell proliferation. C R Acad Sci III 1992;315:473-8.

19 Faury G, Ristori MT, Verdetti J, et al. Effect of elastin peptides on vascular tone. J Vasc Res 1995;32:112-19.

20 Baranek T, Debret R, Antonicelli F, et al. Elastin receptor (spliced galactosidase) occupancy by elastin peptides counteracts pro-inflammatory cytokine expression in lipopolysaccharide-stimulated human monocytes through NF-kappaB down-regulation. J Immunol 2007;179:6184-92.

21 Debret R, Le Naour R, Sallenave JM, et al. Elastin fragments induce IL-1beta upregulation via NF-kappaB pathway in melanoma cells. J Invest Dermatol 2006;126:1860-68.

22 Hinek A, Rabinovitch M, Keeley F, et al. The 67-kD elastin/laminin-binding protein is related to an enzymatically inactive, alternatively spliced form of beta-galactosidase. I Clin Invest 1993:91:1198-205.

23 Duca L, Blanchevoye C, Cantarelli B, et al. The elastin receptor complex transduces signals through the catalytic activity of its $\mathrm{Neu}-1$ subunit. J Biol Chem 2007;282:12484-91.

24 Larbi A, Levesque $G$, Robert $L$, et al. Presence and active synthesis of the $67 \mathrm{kDa}$ elastin-receptor in human circulating white blood cells. Biochem Biophys Res Comm 2005:332:787-92.

25 Mecham RP, Whitehouse L, Hay M, et al. Ligand affinity of the 67-kD elastin/ laminin binding protein is modulated by the protein's lectin domain: visualization of elastin/laminin-receptor complexes with gold-tagged ligands. J Cell Biol 1991;113:187-94.

26 Smith ER, Tomlinson LA, Ford ML, et al. Elastin degradation is associated with progressive aortic stiffening and all-cause mortality in predialysis chronic kidney disease. Hypertension 2012:59:973-8.

27 Debret R, Antonicelli F, Theill A, et al. Elastin-derived peptides induce a T-helper type 1 polarization of human blood lymphocytes. Arterioscler Thromb Vasc Biol 2005;25:1353-58

28 Lee SH, Goswami S, Grudo A, et al. Antielastin autoimmunity in tobacco smoking-induced emphysema. Nat Med 2007;13:567-9.

29 Nowak D, Główczyńska I, Piasecka G. Chemotactic activity of elastin-derived peptides for human polymorphonuclear leukocytes and their effect on hydrogen peroxide and myeloperoxidase release. Arch Immunol Ther Exp 1989;37:741-8.

30 Grosso LE, Scott M. PGAIPG, a repeated hexapeptide of bovine and human tropoelastin, is chemotactic for neutrophils and Lewis lung carcinoma cells. Arch Biochem Biophys 1993:305:401-4.

31 Kreisel D, Nava RG, Li W, et al. In vivo two-photon imaging reveals monocyte-dependent neutrophil extravasation during pulmonary inflammation. Proc Natl Acad Sci USA 2010;107:18073-8.

32 Hurst JR, Wedzicha JA. The biology of a chronic obstructive pulmonary disease exacerbation. Clin Chest Med 2007;28:525-36.

33 Yoshikawa T, Dent G, Ward J, et al. Impaired neutrophil chemotaxis in chronic obstructive pulmonary disease. Am J Respir Crit Care Med 2007:175:473-9.

34 Milara J, Juan G, Peiró $T$, et al. Neutrophil activation in severe, early-onset COPD patients versus healthy non-smoker subjects in vitro: effects of antioxidant therapy. Respiration 2012;83:147-58.

35 Overbeek SA, Braber S, Henricks PA, et al. Cigarette smoke induces $\beta 2$-integrin-dependent neutrophil migration across human endothelium. Respir Res 2011:8:75-86.

36 Hinek A, Keeley FW, Callahan J. Recycling of the 67-kDa elastin binding protein in arterial myocytes is imperative for secretion of tropoelastin. Exp Cell Res 1995:220:312-24. 